\title{
Long-term reintegration and quality of life in patients with subarachnoid hemorrhage and a good neurological outcome: findings after more than 20 years
}

\author{
Bengt Sonesson, PhD, DrMedSci, Erik Kronvall, MD, PhD, Hans Säveland, MD, PhD, \\ Lennart Brandt, MD, PhD, and Ola G. Nilsson, MD, PhD \\ Department of Clinical Sciences, Neurosurgery, Faculty of Medicine, Lund University, Sweden
}

\begin{abstract}
OBJECTIVE The goal of this study was to examine long-term quality of life (QOL) and reintegration in patients with good neurological recovery after aneurysmal subarachnoid hemorrhage (aSAH) and SAH of unknown cause (SAH NUD).

METHODS A long-term follow-up was performed in an original cohort of 113 individuals who had suffered SAH (93 with aSAH and 20 with SAH NUD) between 1977 and 1984. Self-reporting assessments, performed $>20$ years after the bleeding episode, included the Quality of Life Scale (QOLS), Psychological General Well-Being (PGWB) index, and Reintegration to Normal Living (RNL) index, along with information on sleep disturbances and work status.
\end{abstract}

RESULTS Seventy-one survivors were identified. Questionnaires were returned by 67 individuals who had suffered SAH 20-28 years previously. The QOL was rated in the normal range for both the QOLS score (aSAH 90.3 vs SAH NUD 88.6) and the PGWB index (aSAH 105.9 vs SAH NUD 102.8). Ninety percent of patients had returned to their previous employment. Complete RNL was reported by $40 \%$ of patients with aSAH and by $46 \%$ of patients with SAH NUD; mild to moderate readjustment difficulties by $55 \%$ and $38 \%$, respectively; and severe difficulties by $5 \%$ of patients with aSAH and $15 \%$ of patients with SAH NUD. Self-rated aspects of cognition, mood, and energy resources in addition resulted in a substantial drop in overall reintegration. Sleep disturbances were reported by $26 \%$.

CONCLUSIONS More than half of patients with SAH who had early good neurological recovery experienced reintegration difficulties after $>20$ years. However, the general QOL was not adversely affected by this impairment. Inability to return to work after SAH was associated with lower QOLS scores. Sleep disturbances were associated with lower PGWB scores.

https://thejns.org/doi/abs/10.3171/2016.11.JNS16805

KEY WORDS subarachnoid hemorrhage; sleep; Quality of Life Scale; Psychological General Well-Being index; Reintegration to Normal Living index; vascular disorders

$\mathrm{S}$ PONTANEOUS subarachnoid hemorrhage (SAH) many times is a devastating event. When the hemorrhage is caused by a ruptured aneurysm, the case fatality within 1 month is $>30 \%{ }^{16}$ Survival is often at the expense of cognitive or functional impairments. ${ }^{1}$ Global outcome after SAH has usually been stated in broad physical terms such as in the Glasgow Outcome Scale (GOS) $)^{15}$ or the modified Rankin Scale. ${ }^{38}$ Only in more recent years have qualitative aspects been included in the overall out- come assessment. Many investigators have reported data on psychological and neuropsychological consequences following SAH. Reintegration difficulties, with decreased employment rates and reduced independence, have been observed in patients with good neurological status. ${ }^{3,27,41} \mathrm{Im}$ paired quality of life (QOL) has been described in several publications. ${ }^{11,14,31,40,42}$ The reduction has been associated with physical disability 9,12,29,40 but also, even in apparently well-recovered patients, with more subtle sequelae such

ABBREVIATIONS aSAH = aneurysmal subarachnoid hemorrhage; GOS = Glasgow Outcome Scale; PGWB = Psychological General Well-Being; QOL, QOLS = quality of life, QOL Scale; RNL = Reintegration to Normal Living; SAH NUD = SAH of unknown cause.

SUBMITTED April 1, 2016. ACCEPTED November 17, 2016.

INCLUDE WHEN CITING Published online April 28, 2017; DOI: 10.3171/2016.11.JNS16805. 
as cognitive defects, ${ }^{12,24}$ fatigue, ${ }^{39}$ mood disorders, ${ }^{39}$ and sleeping disturbances. ${ }^{34}$ The precise mechanisms underlying such complaints are less known. However, bleeding severity, as assessed by clinical status on hospital admission along with age and sex, has been related to a reduced health-related QOL. ${ }^{14,31,42}$ Neuroendocrine dysfunction resulting from injury to the hypothalamus or pituitary stalk has also been linked to disturbed QOL after SAH. ${ }^{17}$

With respect to the time perspective, psychological follow-up has frequently been focused on the period closest to ictus, ,3, 12,24,25,28,31 and although intermediate or longterm follow-up studies exist, they are limited to the 1st decade after hemorrhage. . $^{14,19,26,33,40,41}$ The purpose of the present study was to examine the consequences of SAH for reintegration and QOL over an extremely long time perspective in patients with a good neurological outcome.

\section{Methods \\ Study Participants}

Between 1977 and 1984, 576 patients with aneurysmal SAH (aSAH) and 101 with SAH of unknown cause (SAH NUD) were admitted to the Department of Neurosurgery in Lund. Of these, 93 patients with aSAH and 20 patients with SAH NUD (i.e., negative results on angiographic studies) who had a good neurological recovery (GOS Score 5) were randomly selected for a neuropsychological assessment and evaluation of adaptation and reintegration in the years after ictus. The results of these initial evaluations were published in $1985,{ }^{20} 1986,{ }^{32} 1987,{ }^{36}$ and $1989 .{ }^{37}$ All patients with aSAH who were selected for study inclusion were in Hunt and Hess Grades I-III on hospital admission ${ }^{13}$ and underwent operation with clip ligation of the ruptured aneurysm. All aneurysms were located in the anterior circulation. Fifty-five patients underwent early surgery ( $<72$ hours) and 38 had late surgery ( $>9$ days), which was then a subject of debate. ${ }^{36}$

The present whereabouts of the 113 patients selected for psychological evaluation were given by the National Population Registry. Mortality data were obtained from the Swedish National Board of Health and Welfare. Thirty-six $(32 \%)$ of the former patients were deceased and 6 were not located. However, only 8 deaths were caused by further cerebrovascular incidents; myocardial complications and tumors were a more frequent cause of death. The mean age of the deceased patients was 70 years. The survivors were contacted and questionnaires (see below) were sent out by mail. A mailing procedure was preferred over telephone or face-to-face contacts so as to give each respondent ample time for afterthought and reflection. Seventy-one survivors gave their consent to participation and were included in the study. The study protocol was approved by the regional ethical review board in Lund.

\section{Follow-Up Evaluation}

Health-related QOL and reintegration after SAH was evaluated by self-assessment questionnaires. There are no instruments pertaining specifically to patients with $\mathrm{SAH}$, so generic instruments had to be used, although such instruments may not be precisely geared to reflect the specific circumstances after $\mathrm{SAH}$. The following protocols, with some additional and supplementary information, were selected to give as broad a view as possible more than 20 years after the illness and recovery. Missing data in the self-assessment questionnaires were estimated using the mean score of the remaining items for the individual concerned.

\section{Quality of Life Scale}

This scale covers material circumstances, physical fitness, relationship to significant others, participation in social activities, learning, creativity, leisure activities, and functional independence. ${ }^{2,7}$ The QOL Scale (QOLS) has been used to assess QOL after heart surgery, ${ }^{22}$ after orthopedic trauma,${ }^{30}$ in fibromyalgia, ${ }^{18}$ and in mild cognitive impairment. ${ }^{8}$ The scale in the version used here consists of 16 items, scored $1-7$, giving the total score a range from 16 to 112 . Higher scores indicate better QOL. The average total score for healthy populations is approximately $90 .{ }^{2}$

\section{Psychological General Well-Being Index}

This index, based on 22 items, yields information over 6 dimensions: anxiety, depression, sense of positive wellbeing, self-control, general health, and vitality. ${ }^{6}$ Each item contains 6 response categories graded 1-6, some of them with a negative syntax. In the analysis, the response to such items is reversed, and the maximum total score of general well-being is 132 . The Psychological General Well-Being (PGWB) index has been used to assess health-related QOL in gastroesophageal reflux disease, ${ }^{5}$ after coronary bypass surgery, ${ }^{35}$ and during treatment for stress-related exhaustion. ${ }^{21}$ Reference values in an extensive Swedish population have been established. ${ }^{5}$ The average total score for a general population is 102.9 , with female norm values slightly below (101.0) and male norm values slightly above (104.5) this point of reference.

\section{Reintegration to Normal Living Index}

This instrument evaluates reintegration in terms of recreation, social activities, participation in the community, and interaction with family and other significant persons. ${ }^{43}$ It has been used to assess reintegration after spinal cord injury, ${ }^{23}$ traumatic brain injury, ${ }^{10}$ stroke, ${ }^{4}$ and up to 5 years after aSAH. ${ }^{3}$

The Reintegration to Normal Living (RNL) scale consists of 11 declarative statements with a positive syntax, and the subject may agree or disagree with these statements along a 10-point axis. A left anchor point of $1 \mathrm{de}-$ notes "Does not describe my situation," and an opposing statement of "Fully describes my situation" is given a rating of 10 . The RNL scores are summed and algebraically converted to an index with a 100-point scale according to the following formula: sum of scores/theoretical maximum sum of scores $\times 100$. The higher the index the better the readjustment and reintegration. An index of 100 is considered to reflect full reintegration; an index between 60 and 99 shows mild to moderate problems of readjustment; and an index of 59 or lower reflects severe problems. ${ }^{3}$

The 11 items included in the original scale have a generic quality and primarily reflect 2 dimensions of general reintegration: daily activities and self-perception. Aspects 


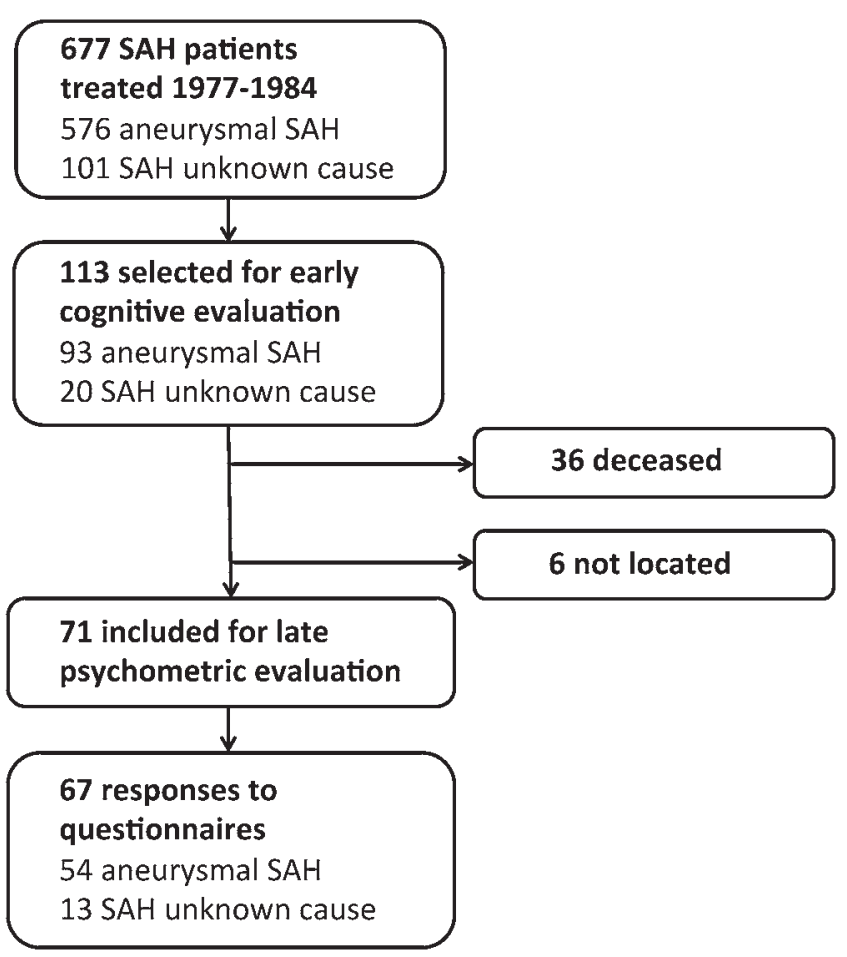

FIG. 1. Flow chart depicting exclusion sequence and SAH characteristics of patients included in the study.

of readjustment known to be specifically sensitive to the effects of intracranial hemorrhage, such as energy resources and energy utilization, vigor, initiative, mood and affective reactions, modulation of emotions, and emotional control are not included. Nor are cognitive aspects such as memory, attention, planning, executive functioning, information processing and speed, flexibility, quality of performance, and similar aspects covered by the scale. These areas of functioning were addressed clinically in the original assessment of this patient cohort in the years following the SAH and have been reported previously. $20,32,36,37$

In accord with the procedure used with the original RNL scale, a number of items reflecting these characteristics were added at the present follow-up. A supplementary 17-item scale was then devised in the manner of the RNL, purporting to yield information with respect to these psychological problem areas and using the findings from the original assessment to define the items of this supplementary scale. Declarative items targeting these aspects were added to the original scale. Each item was similarly scored 1-10. Because the syntax of these latter statements is negative, scores were reversed in the analysis; i.e., the higher the score, the better the outcome and greater the disagreement with the proposed impairment. In the analysis, these items dealing with energy resources, cognition and problem solving, concentration, efficiency, mood, and affect were considered separately. Using the same method as in the original RNL, all scores were converted to a 100-point-scale index.

In addition, information was collected with respect to sleep disturbances and general working capacity. In a separate questionnaire, study participants were asked about
TABLE 1. Clinical characteristics in 67 patients with SAH

\begin{tabular}{|c|c|}
\hline Characteristic & All Respondents \\
\hline Mean age at SAH (range) & 42.1 yrs (17-64 yrs) \\
\hline Female sex & $36(54 \%)$ \\
\hline aSAH & $54(81 \%)$ \\
\hline \multicolumn{2}{|l|}{ Aneurysm location } \\
\hline Anterior communicating artery & $13(19 \%)$ \\
\hline Internal carotid artery & $20(30 \%)$ \\
\hline Middle cerebral artery & $21(31 \%)$ \\
\hline SAH NUD & $13(19 \%)$ \\
\hline Mean time to follow-up (range) & 24.5 yrs (20-28 yrs) \\
\hline Mean age at follow-up (range) & 66.6 yrs (38-87 yrs) \\
\hline
\end{tabular}

problems initiating sleep, problems maintaining sleep, and whether they had returned to work after SAH. Those having returned to work were asked about the extent of their present professional commitment. Those who had subsequently retired from work were asked whether they had received early retirement benefits and at what age they had retired.

\section{Statistical Analysis}

All statistical analyses were performed using SPSS software (IBM Corp.). Univariate and multivariate linear regression models were used to examine variables associated with QOLS and PGWB scores. The variables included were as follows: SAH, sex, age at SAH, age at followup, sleep disturbances, and ability to return to work after $\mathrm{SAH}$. A varimax rotational analysis was used to examine the original and supplementary RNL items to elucidate underlying factors that would possibly be common to both the original and supplementary portions of the scale. Probability values $<0.05$ were considered statistically significant.

\section{Results}

\section{Study Participants}

As stated earlier, 36 of the initially selected 113 patients were deceased at the time of follow-up. Questionnaires were sent out by mail, and eventually 67 of 71 persons returned the requested information; a $94 \%$ response rate (Fig. 1). Clinical characteristics of the 67 included patients are listed in Table 1. Fifty-four had suffered aSAH and 13 had SAH NUD. The mean age at ictus was 41.6 years (range 17-58 years) in patients with aSAH, and it was 44.1 years (range 27-64 years) in patients with SAH NUD. Thirty-six (54\%) of the participants were females. In the aSAH cases, the site of the ruptured aneurysm was the anterior communicating artery in 13 , the internal carotid artery in 20 , and the middle cerebral artery in 21 patients. The mean time from hemorrhage to follow-up was 24.5 years (range 20-28 years). The mean age at follow-up was 66.6 years (range $38-87$ years). In the analysis, patients with SAH NUD were assessed separately.

\section{Sleep Disturbances}

Insomnia was commonly reported in the study popula- 
TABLE 2. The QOLS scores in 66 patients with SAH

\begin{tabular}{rlcc}
\hline \multirow{2}{*}{$\begin{array}{r}\text { Item } \\
\text { No. }\end{array}$} & \multicolumn{1}{c}{ Item Description } & \multicolumn{2}{c}{ Mean Score $( \pm$ SD) } \\
\cline { 3 - 4 } & aSAH & SAH NUD \\
\hline 1 & Material and physical well-being & $6.2(1.0)$ & $6.5(0.5)$ \\
\hline 2 & Health & $5.4(1.4)$ & $5.5(1.7)$ \\
\hline 3 & $\begin{array}{c}\text { Relationships with parents, siblings, } \\
\text { and other relatives }\end{array}$ & $5.9(1.3)$ & $5.6(1.2)$ \\
& Having and raising children & $5.9(1.2)$ & $5.9(1.8)$ \\
\hline 5 & Relationship with spouse or signifi- & $6.3(1.1)$ & $6.3(0.9)$ \\
& cant other & $6.2(0.8)$ & $6.1(1.0)$ \\
\hline 6 & Relationships with friends & $5.2(1.1)$ & $5.5(1.7)$ \\
\hline 7 & Helping and encouraging others & $5.1(1.7)$ & $4.7(1.8)$ \\
\hline 8 & Participating in organizations and & & \\
\hline 9 & public affairs & $4.9(1.5)$ & $4.3(2.0)$ \\
\hline 10 & Undellectual development & $5.7(1.0)$ & $5.8(1.1)$ \\
\hline 11 & Occupational role & $5.7(1.4)$ & $5.3(1.5)$ \\
\hline 12 & Expressing oneself creatively & $4.8(1.6)$ & $5.0(1.8)$ \\
\hline 13 & Socializing & $5.8(1.1)$ & $5.0(1.8)$ \\
\hline 14 & Passive and observational recreation & $6.1(1.0)$ & $6.2(1.0)$ \\
\hline 15 & Active and participatory recreation & $5.0(1.8)$ & $5.2(2.1)$ \\
\hline 16 & Independence, doing for oneself & $6.1(1.1)$ & $5.8(2.1)$ \\
\hline
\end{tabular}

Each item is scored from 1 to 7 , and higher scores reflect better outcome.

tion, affecting 17 of 65 respondents (26\%). Twelve (18\%) experienced problems in initiating sleep, and 12 (18\%) acknowledged problems maintaining sleep.

\section{Working Capacity}

After ictus, 61 of 67 individuals (91\%) had returned to work. Forty-six of the 61 (75\%) eventually resumed a previous full-time job or were working to the same extent as before their illness. Fifteen individuals had returned to work at a level below their previous working capacity. Eleven of these patients directly attributed their reduced working capacity to the ensuing consequences of the hemorrhage. Among the 13 patients with SAH NUD, 9 had returned to full-time employment, 3 were partially retired due to the $\mathrm{SAH}$, and the remaining patient had received pension benefits due to an additional stroke.

At the time of follow-up, 30 individuals had remained employed until retirement, and another 26 were still at work. The remaining 11 individuals had received early retirement benefits. The mean age at retirement was 61.3 years.

\section{Quality of Life Scale Scores}

The QOLS questionnaire was returned by 66 individuals. The mean total score was 89.8 , equaling that of a healthy population. ${ }^{2}$ The scores for patients with SAH NUD and aSAH did not differ from one another; they were 88.6 and 90.3 , respectively. Scores for each of the 16 items are listed in Table 2. Among patients with aSAH, 5 items in the scale received a rating better than 6 , and another 9 items had a mean rating between 5 and 6 . No item received a mean score lower than 4 . The SAH NUD group
TABLE 3. The PGWB scores in 66 patients with SAH

\begin{tabular}{lccc}
\hline \multirow{2}{*}{ Item Description } & \multicolumn{2}{c}{ Mean Score \pm SSD) } & \\
\cline { 2 - 3 } & aSAH & SAH NUD & Reference $^{*}$ \\
\hline $\begin{array}{l}\text { General well- } \\
\text { being; total }\end{array}$ & $105.9(15.0)$ & $104.2(24.9)$ & $102.9(102.1-103.8)$ \\
\hline Anxiety & $25.2(3.4)$ & $24.2(6.7)$ & $24.1(23.9-24.3)$ \\
\hline Depressed mood & $16.1(2.0)$ & $15.7(3.2)$ & $15.5(15.4-15.7)$ \\
\hline $\begin{array}{c}\text { Sense of positive } \\
\text { well-being }\end{array}$ & $16.6(3.4)$ & $16.7(5.2)$ & $16.1(16.0-16.3)$ \\
\hline Self-control & $15.6(2.0)$ & $15.4(3.0)$ & $15.3(15.2-15.4)$ \\
\hline General health & $14.6(3.0)$ & $13.3(3.9)$ & $14.6(14.5-14.8)$ \\
\hline Vitality & $17.8(3.7)$ & $19.0(5.9)$ & $17.2(17.0-17.4)$ \\
\hline
\end{tabular}

* Normative data from Dimenäs et al., 1996. "Reference" denotes a 95\% confidence interval (values in parentheses in last column). Higher scores reflect better outcome.

presented a similar picture; 4 items were rated better than 6 , and 10 were between 5 and 6 . Three missing values for 2 individuals in the latter group were replaced by the mean of the remaining values so as not to compromise the total mean for these patients. The qualities getting the highest ratings were "relationship with spouse or significant other" (6.3) and "relationships with friends" (6.2), ratings that also agreed with the views held by patients with SAH NUD. The feeling of "independence, doing for oneself" was high (6.1), and so were ratings of "material and physical well-being" (6.2) and participation in cultural activities (i.e., "passive and observational recreation") (6.1). The lowest ratings were given to "expressing oneself creatively" (4.8) and "intellectual development" (4.9). All in all, ratings in the SAH NUD group were in accord with those in the patients with aSAH, with only slight and insignificant deviations. In the multivariate regression analysis, lower QOLS scores were found with sleep disturbances $(\beta=-9.5, p=0.021)$ and an inability to return to work $(\beta$ $=-16.8, \mathrm{p}=0.004)$.

\section{Psychological General Well-Being Scores}

The average general well-being score was 105.9 for 53 patients with aSAH who completed the questionnaire and 104.2 for the 13 patients with SAH NUD. The patients with SAH NUD and those with aSAH did not differ significantly from one another across the various dimensions. Dimension scores with normative values are given in Table 3. The average scores in the study population did not differ from reference values in a normal population. In the multivariate regression analysis, lower PGWB scores were found in patients with sleep disturbances $(\beta=-12.8$, $\mathrm{p}=0.013$ ).

\section{Reintegration to Normal Living Scores}

The mean RNL index score was 91.4 for the 54 patients with aSAH who completed the questionnaire. Twenty-two (41\%) patients received an index of 100 . Thirty $(56 \%)$ patients scored in the 60-99 range, indicating mild or moderate reintegration difficulties, and only 2 (4\%) of the former patients reported having major problems in RNL. Among patients with SAH NUD, the mean index score was slight- 
TABLE 4. The RNL scores, with original and supplementary items, in 67 patients with SAH

\begin{tabular}{|c|c|c|c|}
\hline \multirow{2}{*}{$\begin{array}{l}\text { Item } \\
\text { No. }\end{array}$} & \multirow[b]{2}{*}{ Item Description } & \multicolumn{2}{|c|}{ Mean Score $( \pm$ SD) } \\
\hline & & aSAH & SAH NUD \\
\hline \multicolumn{4}{|c|}{ Original } \\
\hline 1 & Moving around living quarters & $9.8(1.0)$ & $7.7(3.7)$ \\
\hline 2 & Moving around community & $9.3(1.9)$ & $8.2(3.1)$ \\
\hline 3 & Take trips out of town & $8.6(3.0)$ & $8.1(3.7)$ \\
\hline 4 & Comfortable with self-care needs & $9.9(0.6)$ & $8.8(2.7)$ \\
\hline 5 & Days occupied in work activity & $9.2(1.7)$ & $8.2(3.4)$ \\
\hline 6 & Participate in recreational activities & $8.8(2.3)$ & $8.2(3.5)$ \\
\hline 7 & Participate in social activities & $9.2(1.7)$ & $9.0(1.9)$ \\
\hline 8 & Assume role in family & $9.2(1.9)$ & $8.6(2.8)$ \\
\hline 9 & Comfortable with personal relationships & $9.2(1.5)$ & $9.2(2.0)$ \\
\hline 10 & $\begin{array}{l}\text { Comfortable with myself in company } \\
\text { of others }\end{array}$ & $8.5(2.2)$ & $8.5(2.8)$ \\
\hline 11 & Deal with life events as they happen & $8.8(1.9)$ & $7.9(3.2)$ \\
\hline \multicolumn{4}{|c|}{ Supplementary } \\
\hline 12 & Need for daytime rest & $4.4(3.8)$ & $3.9(3.8)$ \\
\hline 13 & Fatiguability & $4.1(3.6)$ & $5.7(3.6)$ \\
\hline 14 & Problems with economic management & $7.2(3.3)$ & $7.6(2.7)$ \\
\hline 15 & Staying at home mostly & $5.0(3.6)$ & $5.5(3.8)$ \\
\hline 16 & Lack of interest in others & $5.3(3.7)$ & $5.9(3.8)$ \\
\hline 17 & Poor memory & $5.0(3.5)$ & $4.7(3.5)$ \\
\hline 18 & $\begin{array}{l}\text { Difficulty in problem solving/planning } \\
\text { ahead }\end{array}$ & $6.2(3.2)$ & $7.4(3.1)$ \\
\hline 19 & Problems seeing a job through & $6.6(3.2)$ & $6.9(3.3)$ \\
\hline 20 & Lack of concentration & $6.7(3.0)$ & $7.5(2.9)$ \\
\hline 21 & Impulsivity & $5.5(3.0)$ & $7.5(2.0)$ \\
\hline 22 & Making many mistakes & $7.1(2.5)$ & $7.4(2.5)$ \\
\hline 23 & Confused/bewildered & $6.3(3.3)$ & $6.9(3.3)$ \\
\hline 24 & Slow mental processing & $6.5(3.2)$ & $6.6(3.4)$ \\
\hline 25 & Forgetting appointments and similar & $7.9(3.2)$ & $6.9(3.3)$ \\
\hline 26 & Lack of efficiency at work & $7.1(3.0)$ & $7.1(3.0)$ \\
\hline 27 & Less qualified work & $6.9(3.0)$ & $7.8(3.6)$ \\
\hline 28 & Irritability/bad temper & $5.8(3.6)$ & $6.2(3.8)$ \\
\hline
\end{tabular}

Each item is scored from 1 to 10 . Higher scores reflect better outcome.

ly lower (84.9). Six patients (46\%) had a full readjustment, and another 5 scored in the 60-99 range, indicating mild to moderate reintegration difficulties. The remaining 2 patients had an index $<60$. The questionnaire's content and mean scores for all items are given in Table 4.

Using the same method to compute an index for the supplementary items, a picture quite at variance with the first seemed to emerge. Both SAH groups showed a substantial drop in their self-ratings, the aSAH group to a mean index of 60.9 and the SAH NUD group to 65.6. In particular, supplementary items 12 and 13 ("Need for daytime rest" and "Fatiguability") proved to characterize both groups, as did the cognitive item 17 ("Poor memory"). Clearly, the addition of items dealing with energy assets and cognitive capabilities brought to the forefront some aspects in the long-term reintegration and adjustment not covered by the original scale, but nevertheless provided complementary and valuable information about the subsequent course of life for these patients.

For respondents with aSAH, the 11 items of the original RNL scale and the 17 supplementary items were combined and subjected to a factor analysis. A rotated component matrix (varimax with Kaiser normalization) yielded 4 principal factors explaining more than $64 \%$ of the total variance. The strongest factor to emerge was related to aspects of performance quality (supplementary items: $25,23,24,27$, and 22) and executive functioning (supplementary items: $18,20,17,19,26,21,28$, and 13), followed by social commitment (original items: $9,10,8,7,11$, and 3 ) and social mobility (original items: 1,2, and 5). These items are listed in descending order according to their strength in defining the factor.

\section{Discussion}

This study focused on QOL and reintegration after $\mathrm{SAH}$ in a time perspective of $>20$ years. The study population, representing about $10 \%$ of all admitted patients, included patients with aSAH or SAH NUD, all with a good neurological recovery after 1 year, as assessed by standard outcome measures. A favorable physical outcome, however, does not preclude the possibility that emotional and psychological sequelae may persist and interfere with adaptation and social reintegration in the long run. In the present study, more than 2 decades after the hemorrhage, more than half of these patients still did not feel fully reintegrated. However, this lack of readjustment did not seem to have a significant impact on QOL.

The individuals in the present study constitute the longterm survivors in a cohort of patients with SAH who were referred for neuropsychological assessment between 3 and 7 years after ictus. Functional morbidity in these patients was then demonstrated in terms of intellectual impairment and problems of readjustment. ${ }^{20,32,36,37}$ A majority of the patients were shown to suffer from moderate to severe cognitive impairment at the time of the initial assessment. ${ }^{36}$ There was no relationship between the timing of the neurosurgical intervention, the side or site of the aneurysm, and the degree of cognitive impairment.

Given such cognitive disturbances in these patients with good-grade SAH, one might expect persistent shortcomings in daily life, with consequences for self-realization, emotional and social adjustment, work, leisure activities, and similar aspects in the years subsequent to the hemorrhage. Indeed, this was reflected in the reintegration difficulties reported through the supplementary questionnaire to the RNL in the present evaluation. Evidently, these phenomena do not seem to wane over time, but their impact may be felt for a great many years after the ictus.

In the assessment of long-term adjustment and reintegration, the use of available inventories was considered but abandoned in favor of a specifically structured approach. There was a need for an inventory resting on specific aspects of adaptation and readjustment that would be conceived of as relevant in content for the former patients. No single inventory was found to comprise all subject areas of presumed importance. In view of such limitations of 
existing inventories, relevant subject areas were then compiled into a supplementary RNL scale to elucidate aspects known to be sensitive to the effects of SAH. The factor analysis performed on the original items of the RNL scale as well as the supplementary items revealed diverse aspects of reintegration and adjustment. Whereas the original scale primarily elucidated aspects of commitment and social participation, the supplementary scale contributed information related to cognition, mental control, and executive functioning as well as mood and energy management; aspects not covered by the original RNL scale. Clearly, the factors emerging from the factor analysis represent different but nevertheless significant expressions and dimensions of underlying difficulties during years of readjustment and adaptation.

The original RNL scale was left uncompromised and pure. The additional items would provide specific information sensitive to circumstances possibly emerging from the $\mathrm{SAH}$, as evidenced in the original studies on these patients in the intermediate years following the bleed. Among these supplementary items specifically devised to address psychological and neuropsychological problems commonly seen after $\mathrm{SAH}$, findings were consistent in quality with what was observed in the original evaluation in the post-SAH years. None of the items of the original RNL scale stood out as particularly severely affected, and no single mean score in the supplementary scale exceeded the lowest mean score in the original RNL scale among patients with aSAH. The mean index score of the 17 supplementary items was considerably lower than the index for the original items: 60.9 versus 91.4 for the aSAH group and 65.6 versus 84.9 for the SAH NUD group.

Quality of life, as assessed by QOLS and PGWB, was not reduced in the study population as a whole. Although studies with long-term QOL follow-up after SAH are scarce, similar findings have been reported. Assessment by the Short Form-36 Health Survey in patients with good recovery (GOS Score 5) 4.7 years after SAH did not show significant reductions compared with healthy controls, except with respect to general health and social functioning. ${ }^{33}$ Evaluation by the EuroQol-5 Dimensions ${ }^{40}$ health survey 10 years after SAH revealed reduced indices compared with controls. In patients with favorable outcome (GOS Score 4-5) this reduction was only modest.

In the present study, the average total QOLS scores of 90.3 in patients with aSAH and 88.6 in patients with SAH NUD equal the approximately 90 score stated for healthy controls, ${ }^{2}$ and the mean total PGWB scores of 105.9 in the aSAH group versus 104.2 among patients with SAH NUD compare favorably to the norm value of 102.9 in an extensive control group. ${ }^{5}$ However, relative QOL impairments were seen in subgroups. Of the 2 QOL measures, QOLS is more oriented toward social aspects, whereas PGWB is more oriented toward health-related issues. This is probably reflected in lower QOLS scores but not lower PGWB scores among those unable to return to work. With respect to sex, PGWB scores tended to be lower for female patients, but this difference was not statistically significant. This trend was also in agreement with normative data. Sleep disorders were associated with impaired QOL as measured with both scales. Sleep disorders in our cohort (26\%) were roughly as common as what has been reported
1-3.4 years after SAH (34\%), ${ }^{34}$ and were similarly associated with reduced QOL.

The major limitation of this study pertains to the characteristics of patients with SAH in the original studies. Only SAH survivors with a favorable 1-year recovery were then randomly selected and subjected to an extensive neuropsychological evaluation. These patients eventually became the participants in the present study. Thus, the results are probably not applicable to poor-grade patients.

Another limitation inherent to the study design lies in the passing of many years before follow-up. This will make patients who were younger at the time of SAH more likely to be included. However, the clinical course for this subgroup of patients with SAH is particularly important to examine. Identifying factors associated with increased risk of reduced QOL may help improve the care of these patients over a very long time.

Comparing our results with data from other investigators, an earlier study that included psychosocial evaluation 4-7 years after SAH showed that $41 \%$ of participants suffered from memory problems, $35 \%$ had daytime sleepiness, and $26 \%$ had difficulty sleeping at nighttime. Another study reported personality changes, such as irritability and apathy in 59\% and memory changes in $35 \%$ of patients 8.9 years after $\mathrm{SAH} .{ }^{41}$ Evaluation by RNL in patients with SAH who had been in good neurological condition on hospital admission showed impaired reintegration in $45 \%$ of these individuals $1-5$ years later. ${ }^{3}$ Our new data confirm that such problems may persist for $>20$ years after SAH.

With respect to the passing of years after the hemorrhage, the course of life itself and a variety of key events will have an impact on each individual and exert their influence in different ways and in different directions. It is likely that other health issues and social and economic conditions have occurred to influence the adjustment and QOL in our former patients, and so have other events that come with the passing of time. By the same token, such events will also exert an influence on individuals in the control groups. It was beyond the scope of this study to control for such external factors, and it is even less feasible to reach an understanding of such events among control volunteers. It might be assumed, however, and with a reasonable degree of certainty, that the participants in this study, having survived $>20$ years after their ictus, do not differ in other relevant aspects from controls. However, the influence of the once-devastating cerebrovascular illness and its ensuing concomitant effects among our patients can neither be disregarded nor ruled out. The chosen path is then to let the former patients rate their life situation using their own judgment and reflections about a number of factual and relevant issues. This study then adopts the objective of portraying and describing the present situation for the former patients without attempting to view their situation in terms of cause and effect.

\section{Conclusions}

At an average of 24.5 years after spontaneous SAH, there was no reduction in QOL in our study population as a whole. Nonetheless, impaired QOL was seen in subgroups: in those with sleep disorders and in those who had not been able to return to work after SAH. A significant 
number of individuals still experienced reintegration difficulties even though their general QOL was reportedly good and equaled that of a healthy population. To our knowledge, this is by far the longest follow-up time for such data. The results shed new light on the course of recovery post-SAH and emphasize the need for rehabilitation efforts and continuous support, even in patients with apparently good outcome after SAH.

\section{References}

1. Al-Khindi T, Macdonald RL, Schweizer TA: Cognitive and functional outcome after aneurysmal subarachnoid hemorrhage. Stroke 41:e519-e536, 2010

2. Burckhardt CS, Anderson KL: The Quality of Life Scale (QOLS): reliability, validity, and utilization. Health Qual Life Outcomes 1:60, 2003

3. Carter BS, Buckley D, Ferraro R, Rordorf G, Ogilvy CS: Factors associated with reintegration to normal living after subarachnoid hemorrhage. Neurosurgery 46:1326-1334, 2000

4. Daneski K, Coshall C, Tilling K, Wolfe CDA: Reliability and validity of a postal version of the Reintegration to Normal Living Index, modified for use with stroke patients. Clin Rehabil 17:835-839, 2003

5. Dimenäs E, Carlsson G, Glise H, Israelsson B, Wiklund I: Relevance of norm values as part of the documentation of quality of life instruments for use in upper gastrointestinal disease. Scand J Gastroenterol Suppl 221:8-13, 1996

6. Dupuy HJ: The Psychological General Well-Being (PGWB) Index, in Wenger NK, Mattson ME, Furberg CF, et al (eds): Assessment of Quality of Life in Clinical Trials of Cardiovascular Therapies. New York: Le Jacq, 1984, pp 170183

7. Flanagan JC: A research approach to improving our quality of life. Am Psychol 33:138-147, 1978

8. Gates N, Valenzuela M, Sachdev PS, Singh MA: Psychological well-being in individuals with mild cognitive impairment. Clin Interv Aging 9:779-792, 2014

9. Hackett ML, Anderson CS: Health outcomes 1 year after subarachnoid hemorrhage: An international population-based study. Neurology 55:658-662, 2000

10. Harker WF, Dawson DR, Boschen KA, Stuss DT: A comparison of independent living outcomes following traumatic brain injury and spinal cord injury. Int J Rehabil Res 25:93-102, 2002

11. Hop JW, Rinkel GJ, Algra A, van Gijn J: Changes in functional outcome and quality of life in patients and caregivers after aneurysmal subarachnoid hemorrhage. J Neurosurg 95:957-963, 2001

12. Hop JW, Rinkel GJ, Algra A, van Gijn J: Quality of life in patients and partners after aneurysmal subarachnoid hemorrhage. Stroke 29:798-804, 1998

13. Hunt WE, Hess RM: Surgical risk as related to time of intervention in the repair of intracranial aneurysms. J Neurosurg 28:14-20, 1968

14. Hütter BO, Kreitschmann-Andermahr I, Gilsbach JM: Health-related quality of life after aneurysmal subarachnoid hemorrhage: impacts of bleeding severity, computerized tomography findings, surgery, vasospasm, and neurological grade. J Neurosurg 94:241-251, 2001

15. Jennett B, Bond M: Assessment of outcome after severe brain damage. Lancet 1:480-484, 1975

16. Koffijberg H, Buskens E, Granath F, Adami J, Ekbom A, Rinkel GJE, et al: Subarachnoid haemorrhage in Sweden 1987-2002: regional incidence and case fatality rates. J Neurol Neurosurg Psychiatry 79:294-299, 2008

17. Kreitschmann-Andermahr I, Poll E, Hütter BO, Reineke A, Kristes S, Gilsbach JM, et al: Quality of life and psychiatric sequelae following aneurysmal subarachnoid haemorrhage: does neuroendocrine dysfunction play a role? Clin Endocrinol (Oxf) 66:833-837, 2007

18. Liedberg GM, Björk M, Börsbo B: Self-reported nonrestorative sleep in fibromyalgia-relationship to impairments of body functions, personal function factors, and quality of life. J Pain Res 8:499-505, 2015

19. Lindberg M, Ängquist KA, Fodstad H, Fugl-Meyer K, FuglMeyer AR: Self-reported prevalence of disability after subarachnoid haemorrhage, with special emphasis on return to leisure and work. Br J Neurosurg 6:297-304, 1992

20. Ljunggren B, Sonesson B, Säveland H, Brandt L: Cognitive impairment and adjustment in patients without neurological deficits after aneurysmal SAH and early operation. J Neurosurg 62:673-679, 1985

21. Lundgren-Nilsson Å, Jonsdottir IH, Ahlborg G Jr, Tennant A: Construct validity of the Psychological General Well Being Index (PGWBI) in a sample of patients undergoing treatment for stress-related exhaustion: a Rasch analysis. Health Qual Life Outcomes 11:2, 2013

22. Mathisen L, Andersen MH, Veenstra M, Wahl AK, Hanestad BR, Fosse E: Quality of life can both influence and be an outcome of general health perceptions after heart surgery. Health Qual Life Outcomes 5:27, 2007

23. May LA, Warren S: Measuring quality of life of persons with spinal cord injury: external and structural validity. Spinal Cord 40:341-350, 2002

24. Mayer SA, Kreiter KT, Copeland D, Bernardini GL, Bates JE, Peery S, et al: Global and domain-specific cognitive impairment and outcome after subarachnoid hemorrhage. Neurology 59:1750-1758, 2002

25. McKenna P, Willison JR, Phil B, Lowe D, Neil-Dwyer G: Cognitive outcome and quality of life one year after subarachnoid haemorrhage. Neurosurgery 24:361-367, 1989

26. Ogden JA, Utley T, Mee EW: Neurological and psychosocial outcome 4 to 7 years after subarachnoid hemorrhage. Neurosurgery 41:25-34, 1997

27. Powell J, Kitchen N, Heslin J, Greenwood R: Psychosocial outcomes at 18 months after good neurological recovery from aneurysmal subarachnoid haemorrhage. J Neurol Neurosurg Psychiatry 75:1119-1124, 2004

28. Powell J, Kitchen N, Heslin J, Greenwood R: Psychosocial outcomes at three and nine months after good neurological recovery from aneurysmal subarachnoid haemorrhage: predictors and prognosis. J Neurol Neurosurg Psychiatry 72:772-781, 2002

29. Quinn AC, Bhargava D, Al-Tamimi YZ, Clark MJ, Ross SA, Tennant A: Self-perceived health status following aneurysmal subarachnoid haemorrhage: a cohort study. BMJ Open 4:e003932, 2014

30. Rohde G, Haugeberg G, Mengshoel AM, Moum T, Wahl AK: Is global quality of life reduced before fracture in patients with low-energy wrist or hip fracture? A comparison with matched controls. Health Qual Life Outcomes 6:90, 2008

31. Ronne-Engström E, Enblad P, Lundström E: Outcome after spontaneous subarachnoid hemorrhage measured with the EQ-5D. Stroke 42:3284-3286, 2011

32. Säveland H, Sonesson B, Ljunggren B, Brandt L, Uski T, Zygmunt $\mathrm{S}$, et al: Outcome evaluation following subarachnoid hemorrhage. J Neurosurg 64:191-196, 1986

33. Scharbrodt W, Stein M, Schreiber V, Böker DK, Oertel MF: The prediction of long-term outcome after subarachnoid hemorrhage as measured by the Short Form-36 Health Survey. J Clin Neurosci 16:1409-1413, 2009

34. Schuiling WJ, Rinkel GJ, Walchenbach R, de Weerd AW: Disorders of sleep and wake in patients after subarachnoid hemorrhage. Stroke 36:578-582, 2005

35. Sjöland H, Wiklund I, Caidahl K, Hartford M, Karlsson T, Herlitz J: Improvement in quality of life differs between 
women and men after coronary artery bypass surgery. J Intern Med 245:445-454, 1999

36. Sonesson B, Ljunggren B, Säveland H, Brandt L: Cognition and adjustment after late and early operation for ruptured aneurysm. Neurosurgery 21:279-287, 1987

37. Sonesson B, Säveland H, Ljunggren B, Brandt L: Cognitive functioning after subarachnoid haemorrhage of unknown origin. Acta Neurol Scand 80:400-410, 1989

38. van Swieten JC, Koudstaal PJ, Visser MC, Schouten HJ, van Gijn J: Interobserver agreement for the assessment of handicap in stroke patients. Stroke 19:604-607, 1988

39. Visser-Meily JMA, Rhebergen ML, Rinkel GJE, van Zandvoort MJ, Post MWM: Long-term health-related quality of life after aneurysmal subarachnoid hemorrhage: relationship with psychological symptoms and personality characteristics. Stroke 40:1526-1529, 2009

40. von Vogelsang AC, Burström K, Wengström Y, Svensson M, Forsberg C: Health-related quality of life 10 years after intracranial aneurysm rupture: a retrospective cohort study using EQ-5D. Neurosurgery 72:397-406, 2013

41. Wermer MJ, Kool H, Albrecht KW, Rinkel GJE: Subarachnoid hemorrhage treated with clipping: long-term effects on employment, relationships, personality, and mood. Neurosurgery 60:91-98, 2007

42. Wong GKC, Poon WS, Boet R, Chan MTV, Gin T, Ng SCP, et al: Health-related quality of life after aneurysmal subarachnoid hemorrhage: profile and clinical factors. Neurosurgery 68:1556-1561, 2011
43. Wood-Dauphinee SL, Opzoomer MA, Williams JI, Marchand B, Spitzer WO: Assessment of global function: The Reintegration to Normal Living Index. Arch Phys Med Rehabil 69:583-590, 1988

\section{Disclosures}

The authors report no conflict of interest concerning the materials or methods used in this study or the findings specified in this paper.

\section{Author Contributions}

Conception and design: Sonesson, Säveland, Brandt. Acquisition of data: Sonesson. Analysis and interpretation of data: Sonesson, Kronvall, Nilsson. Drafting the article: Sonesson, Kronvall. Critically revising the article: all authors. Reviewed submitted version of manuscript: all authors. Approved the final version of the manuscript on behalf of all authors: Sonesson. Statistical analysis: Sonesson, Kronvall. Administrative/technical/material support: Säveland, Brandt, Nilsson.

\section{Correspondence}

Bengt Sonesson, Department of Clinical Sciences, Neurosurgery, Faculty of Medicine, Lund University, Lund S-22185, Sweden. email: bengtsones@gmail.com. 